\title{
Research and Analysis on incentive mechanism of teaching quality assurance in colleges and universities
}

\author{
Liman Zhao ${ }^{1, a}$, Xiaoyun Chen ${ }^{1, b}$ \\ ${ }^{1}$ Jiangxi Science \& Technology Normal University, Nanchang, Jiangxi, 330013, China \\ alimzhao@126.com, ${ }^{b} 40905438 @ q q . c o m$
}

\begin{abstract}
Keywords: Teaching quality of colleges and universities; guarantee; incentive mechanism; research; analysis
\end{abstract}

\begin{abstract}
Because the development of the socialist market economy has been accelerating, people have begun to pay attention to the study of basic education in order to cater to the development of the society based on the influence of the environment. Therefore, all colleges and universities in order to improve the teaching quality of the whole school, in addition to the process of school management in the process of applying the theory of fairness, but also the establishment of incentive mechanism. Therefore, this article is according to the present teaching situation, the fair theory, people-oriented teaching and incentive mechanism of the appropriate application to the present teaching of colleges and universities, so as to realize the improve the teaching quality of colleges and universities.
\end{abstract}

\section{Introduction}

Motivation mainly refers to the use of some material or spiritual power to inspire people's work enthusiasm and efficiency. The concept of incentive theory is mainly said in a unique way and management mode, so that the staff of enterprises and their own contribution to the work of the nature of the greatest benefits of the process. Motivation theory can not only stimulate people's enthusiasm for work, but also can effectively improve the efficiency of the whole work. Further investigation shows that the incentive theory is applied to various fields, which not only can urge people to move forward, but also stimulate the enthusiasm of people's work. However, before doing everything according to the actual situation to make the right judgment after the execution, and thus to ensure the quality of the whole work. Therefore, this article on how to improve the teaching quality of colleges and universities, according to the incentive mechanism to improve the quality of teaching research and analysis. This paper mainly from three aspects of the incentive mechanism for a detailed exposition: the first part of the main introduction of incentive theory. The second part mainly analyzes the important role of incentive strategy in the management of teachers. Third aspects of the incentive mechanism to introduce the specific application of teaching management in Colleges and universities. Below will further explain the incentive mechanism in the university teaching application and the development direction.

\section{Incentive theory connotation}

Incentive theory is mainly refers to the use of some material or spiritual power to stimulate people's work enthusiasm and efficiency, and then the people's own potential and innovative ability to fully play. Noted American psychologist William James has done an experiment on motivation. Experimental results show that when a person at work, if there is no certain incentive and his potential ability and innovation ability can only play to about 25\%; when a person at work, if you get a certain incentive and his potential ability and innovation ability can play to $85 \%$. As a result, we can fully see the importance of incentive programs for people. Therefore, in order to improve the overall teaching quality of colleges and universities, it is appropriate to apply incentive mechanism in teaching management. A good incentive mechanism not only can improve the quality of teaching in the whole school, but also can promote the development of better schools in the future. If the incentive 
mechanism is not appropriate, it will not only affect the overall effect of the school, but also on the future development of the cause of the school led to a certain degree of influence.

\section{The important role of the incentive mechanism to the College Teachers}

3.1 Powerful driving force for the development of practical teaching in Colleges and Universities In the present teaching management process, in order to improve students' creativity and practical ability, all colleges and universities should implement the practice teaching mode. This teaching model mainly focuses on five aspects to carry on the reform. The first is the teaching idea; the second is to carry out the fundamental principles of the teaching; the third is to improve the practice of teaching mode; the fourth is the kinds of practice teaching innovation; the fifth is to improve the teaching practice of the overall water quasi. In order to practice teaching can achieve the desired teaching effect, the most important factor is the practice of teachers. In the process of teaching management, there are many factors that lead to the negative phenomenon of teachers' work, including social factors, school factors, interpersonal factors and personal factors. But no matter what the factors, in order to stimulate the enthusiasm of teachers, it is appropriate to use the incentive mechanism. Good incentive mechanism, not only can improve the quality of the whole teaching, but also can promote the better development of practice teaching in Colleges and universities.

3.2 The important guarantee of the stable practice teacher troop

According to the present teaching situation, because of the traditional teaching philosophy in our country present stage teaching effect quite deep, many schools there are emphasis on basic theories, pay attention to examination results, but ignore cultivation of the practical ability of students, to train students to become the test machine, this phenomenon directly to our country present teaching ideas and teaching methods brought huge impact. In a word, the traditional management mode is unable to meet the modern school management mode, it has been unable to follow up the pace of modernization progress, in order to improve the school overall teaching quality and comprehensive management model, the teaching practice to the present teaching management to outside, but also the incentive mechanism is applied to the management now. This not only can improve the enthusiasm of the work of teachers in practice, but also can improve the overall quality of teaching in Colleges and universities.

3.3 Effectively tap the potential of teachers in practice

In the present teaching of colleges and universities, the practice of teachers is the key group to improve the quality of teaching in Colleges and universities. Therefore, in order to improve the quality of teaching in Colleges and universities, in addition to the practice of teachers to have a higher professional knowledge, but also have a relatively rich experience in practice. Therefore, in order to improve the teaching quality of colleges and universities, fully meet the needs of practice teachers, so they can be given full play in their work will be their talents and skills, and to improve the working enthusiasm of the teachers' practice. And appropriate incentive mechanism is applied to practical teaching, which can effectively stimulate the creative ability and enthusiasm of teachers.

\section{The application of incentive theory in the teaching management of colleges and Universities}

\subsection{Create a harmonious atmosphere for learning environment}

In order to improve the whole teaching quality, all colleges and universities should create a harmonious learning atmosphere in addition to create a stimulating environment. This is in this environment, the students' learning potential and innovation ability can be fully played. And the students' learning potential ability is strong in the period of high school break. Therefore, in order to stimulate the enthusiasm of students and provide the quality of student learning, it is necessary to appropriate the incentive mechanism, and proceed mainly from two aspects, first is to develop and improve the incentive system; the second is to set up a reasonable incentive mechanism. In order to realize the two aspects of the content, the following is the author of the two aspects of the detailed introduction. 


\subsubsection{To develop a sound incentive system}

The establishment of incentive system can not only exist in oral, to implement the actual teaching management, and let each student can feel the existence of incentive system. In the establishment of incentive system, all the teachers need to be negotiated with all the teachers, and thus ensure that the incentive system has the characteristics of diversity.

4.1.2 Establish a reasonable reward and punishment mechanism

Reward and punishment mechanism of the system, not only can be used to stimulate the motivation of students to learn the way, but also to the performance of the students do not provide a wake-up call for the purpose of. But in the establishment of reward and punishment mechanism, to be combined with the actual situation of the establishment of a reasonable, so that not only can give full play to the incentive effect, but also to the students to establish a long-term goal.

4.2 Follow the principle of fairness

In order to establish a correct concept of fairness, foster fair culture, first of all you have to do is to make the students and the school of management clear, people's sense of fairness from the very strong subjectivity, and the subjectivity of the source to the people, a lot of factors, such as of objective things, the cognitive level, people's values and behavior of people is, its behavior standards and so on. So school administrators to strengthen the cultivation of students' value outlook and outlook on life, improve their ideological awareness and comprehensive quality, establish a correct concept of fairness, objectively pay every time test scores and learning efforts. Do not particularly care about the results and the ranking of each school, the school to give students a relaxed and happy learning atmosphere and students to show themselves the opportunity to let the students understand the collective life of happiness. In order to create a fair, just and open learning environment for students, the first school to do is to the students to establish correct fair view, secondly, the development of students' cultural fair, thus fundamentally avoid sense of injustice caused by students' subjective errors in judgment.

4.3 Rational use of material motivation and spiritual motivation

In order to give full play to the role of the incentive mechanism to the quality of teaching in Colleges and universities, we should use the material and spiritual motivation. Material incentives mainly refers to the school to set up a part of money incentives, this incentive mechanism can not only stimulate students' learning motivation, while those who do not have a good student to cancel the qualification of the scholarship. Spiritual motivation is mainly refers to the sense of honor because everyone has a certain sense of honor, and the spirit of motivation is to stimulate the students' sense of honor, and to achieve the purpose of improving the enthusiasm of learning.

\section{Summary}

Through the elaboration of this article, we have a more in-depth understanding of teaching management in Colleges and universities. And the incentive mechanism is applied to the management of college teaching, not only can stimulate the enthusiasm of teachers, but also can improve the quality of teaching in Colleges and universities. Because, to incentive mechanism is applied to the management of teaching in Colleges and universities now, we need to begin to do the from the three aspects, the first is create a motivating environment harmonious study atmosphere; the second aspect is to follow the principle of fairness; the third is reasonable use of material and spirit incentive. This has only to do these three aspects, in order to highlight the importance of incentive mechanism in the teaching management of colleges and universities in china. Hope that through this paper, we can provide some help for the future development of College Teaching in china.

This paper is the research and practice of teaching quality evaluation system of College Teachers' education and teaching reform in Colleges and Universities: a case study of Jiangxi Science \& Technology Normal University as an example. The Topic number of the research: JXJG-15-10-20 


\section{References}

[1] Zheng Jieqin. Study on the incentive mechanism of university teachers [J]. Journal of Zhangzhou Normal University (PHILOSOPHY AND SOCIAL SCIENCE EDITION), 2008,02:135-139.

[2] high brightness, Yang Qu, Jirong. Based on incentive theory of college teaching quality guarantee system design [J]. Chengdu University of Technology (SOCIAL SCIENCE EDITION), 2008,03:78-82.

[3] Fu Ping. Research on the incentive and guarantee mechanism for the teaching of college teachers [J]. economist, 2015,10:207-208.

[4] Cai ya. Application of analytic motivation theory in the teaching management of colleges and universities [J]. Journal of Hubei University of science and technology, 2014,05:94-95.

2012,03:340-343+347.

[5] Zhang Dongxian, Ai Hua Xie. The incentive mechanism of teaching secretaries in Colleges and universities survey research -- GJ college survey [J]. Modern marketing,. Based on that 2014,08:68-71.

[6] Wang Haibo. Experimental teaching team in Colleges and universities incentive mechanism [J]. Experimental technology and management 